\title{
APLIKASI SKETSA GAMBAR DAN TULISAN PADA VIDEO CALL BERBASIS ANDROID
}

\author{
Anton Setiawan H. ${ }^{1}$, Asih Pujiastuti ${ }^{2}$, Vendy Yuda Saputra ${ }^{3}$ \\ Program Studi Teknik Informatika \\ Sekolah Tinggi Teknologi Adisutjipto Yogyakarta \\ anton@stta.ac.id ${ }_{2}$ asihpuji@stta.ac.id ${ }^{2}$, vendysaputra@gmail.com ${ }^{3}$
}

\begin{abstract}
Video Call is a set of interactive telecommunication technologies which allow two parties of people in different locations can interact via two-way delivery of audio and video in real time. Tools to sketch pictures and writings on the application ViCall aims to facilitate educators do the learning process using media with video call implementation sketch pictures and writings as explanatory. Educators start doing sketches image and writings and then saved. After that upload sketches image and writings made by educators can then be shown to the students. The results of the testing of the application can be run on at least speksifikasi android kitkat v4.4.4. On testing provider obtained the average connection time 8.33 seconds. Based on a questionnaire, test this application generates $84.4 \%$ by criteria of "very good".
\end{abstract}

Keywords : video call, android, distance learning, sketch image.

\section{Pendahuluan}

Video Call(Vicall) adalah seperangkat teknologi telekomunikasi interaktif yang memungkinkan dua pihak di lokasi berbeda dapat berinteraksi melalui pengiriman dua arah audio dan video secara real time. Pemanfaatan dari Video call salah satunya untuk membantu pemeratan informasi. Salah satu pemanfaatan video call dapat digunakan untuk pembelajaran. Pembelajaran adalah suatu proses interaksi peserta didik dengan pendidik dan bertukar informasi antara pendidik dan peserta didik pada suatu lingkungan belajar. Jadi pemanfaatan video call dapat digunakan untuk pertukaran informasi antara pendidik dengan peserta didik.

Video call dapat digunakan sebagai sarana pembelajaran, tetapi tools pada aplikasi masih kurang lengkap. Kekurangan aplikasi Video call misalnya, seorang pendidik menjelaskan suatu rumus atau simbol kepada peserta didik hanya menggunakan percakapan saja, maka peserta didik belum tentu paham tentang penjelasan seorang pendidik tersebut. Video call dapat ditambahkan sebuah tools sebagai media menulis seorang pendidik untuk mempermudah pemahaman peserta didik saat proses belajar mengajar.

\section{Landasan Teori}

\subsection{Sketsa}

Defenisi Sketsa adalah gambar sederhana atau draf kasar yang melukiskan bagian-bagian pokok tanpa detail. Dalam menggunakan sketsa, pendidik dapat menuangkan ide-ide ke dalam bentuk gambar sederhana atau menuliskan draf kasar, yang dapat digunakan dalam proses pembelajaran.

\section{Perancangan Sistem}

\subsection{Use Case Diagram Pendidik}

Dalam use case menggambarkan interaksi seorang aktor dari sebuah sistem yang akan dibangun. Perancangan use case pendidik pada aplikasi ViCall dapat dilihat pada Gambar 1. 


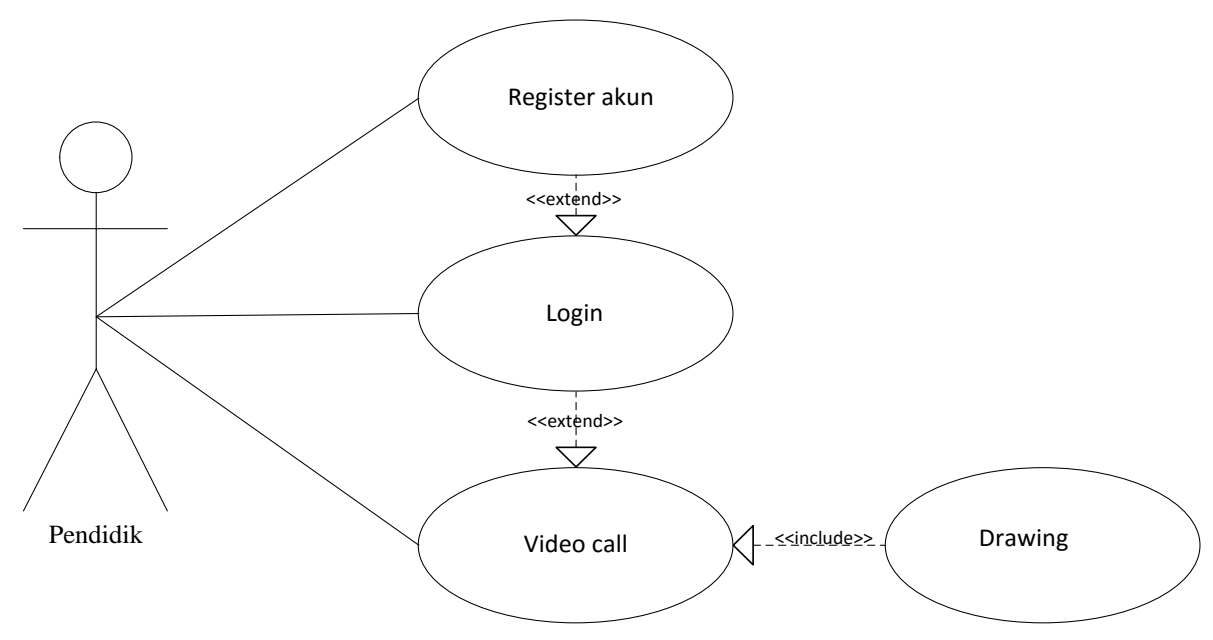

Gambar 1. Use Case Diagram Pendidik

\subsection{Use Case Diagram Peserta Didik}

Gambar 2 menjelaskan use case diagram dari peserta didik aplikasi ViCall. User peserta didik harus melakukan login terlebih dahulu dengan masukkan username setelah masuk menu utama akan memulai video call.

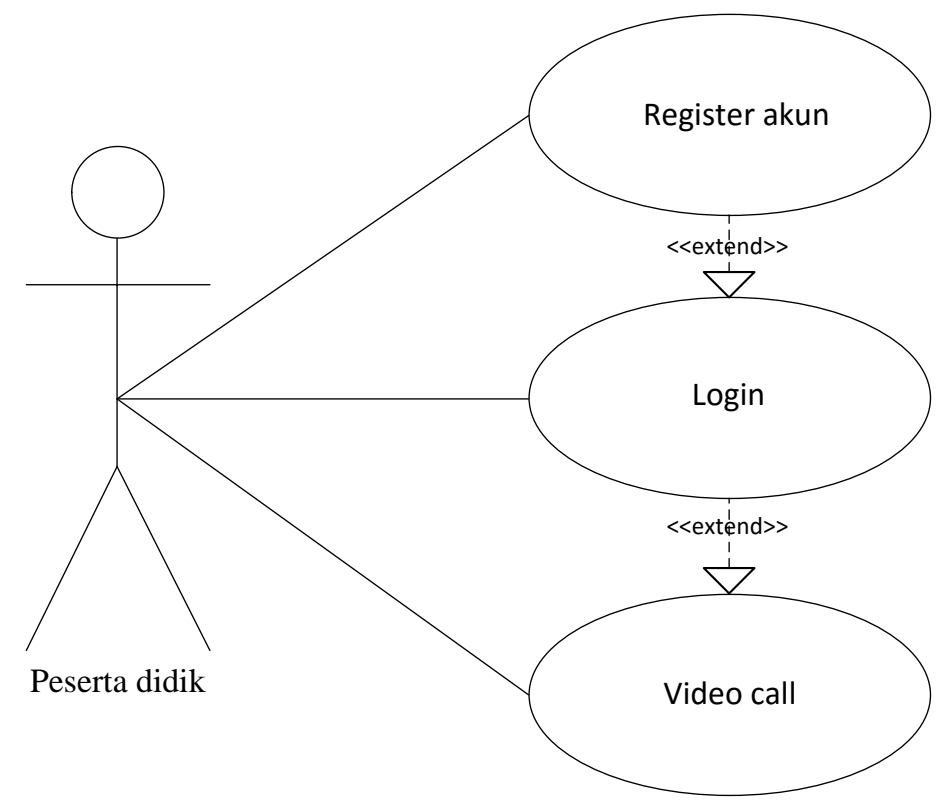

Gambar 2. Use Case Diagram Peserta Didik 


\subsection{Activity Diagram Drawing}

Tabel 1. Activity Diagram Drawing

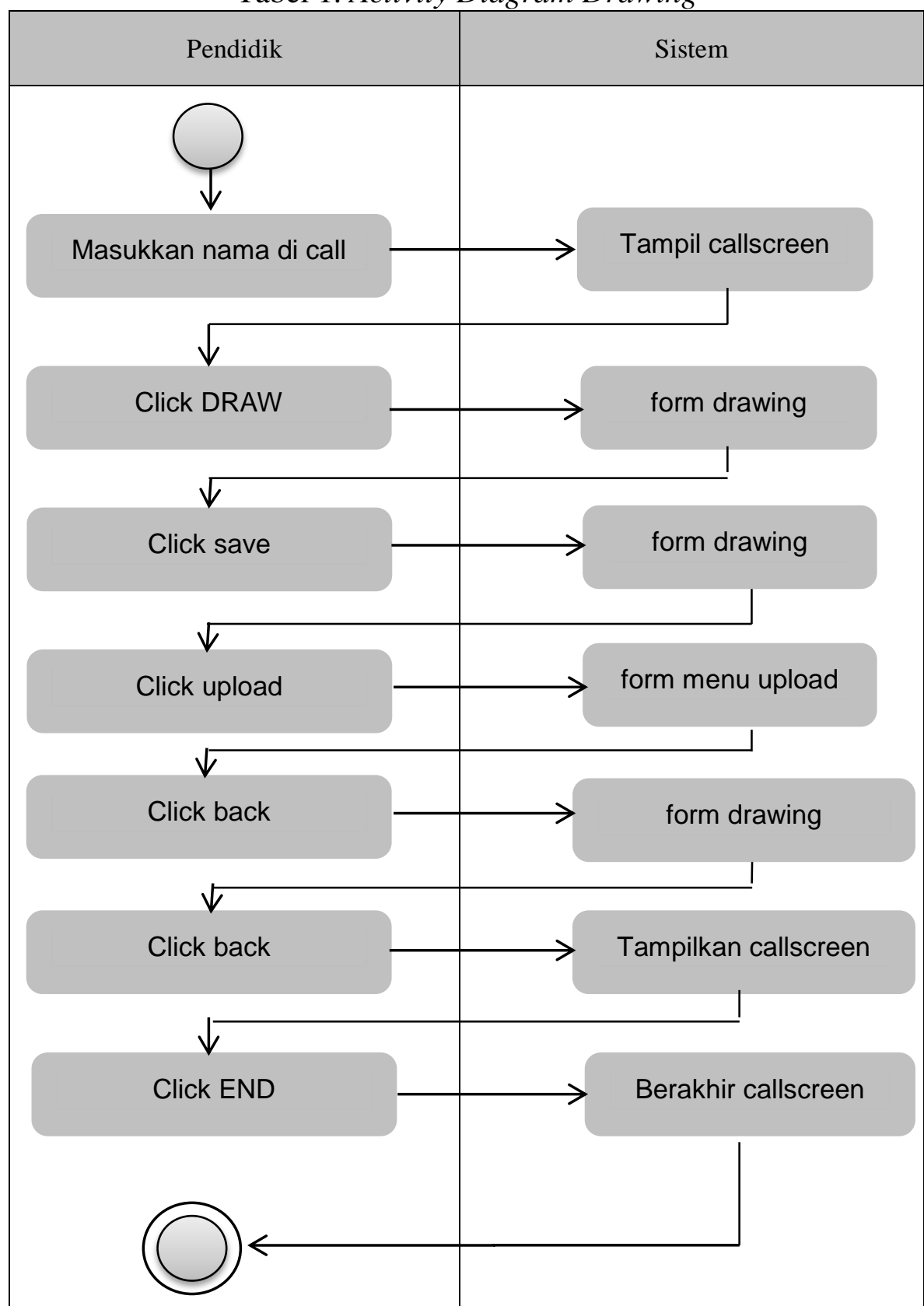

Tabel 1. Activity Diagram Drawing ini, alur proses dimulai menyentuh tombol draw pada pojok kiri bawah dari smartphone, kemudian sistem akan ke halaman drawing. Pada halaman drawing pendidik bisa melakukan sketsa gambar dan tulisan lalu menyimpan terlebih dahulu kemudian di upload agar bisa ditampilkan pada peserta didik.

\subsection{Sequence Diagram Login}

Perancangan Sequence Diagram menggambarkan interaksi obyek di dalam dan di sekitar sistem berupa message yang digambarkan terhadap waktu. Rancangan sequence diagram dapat dilihat pada Gambar 3 . 


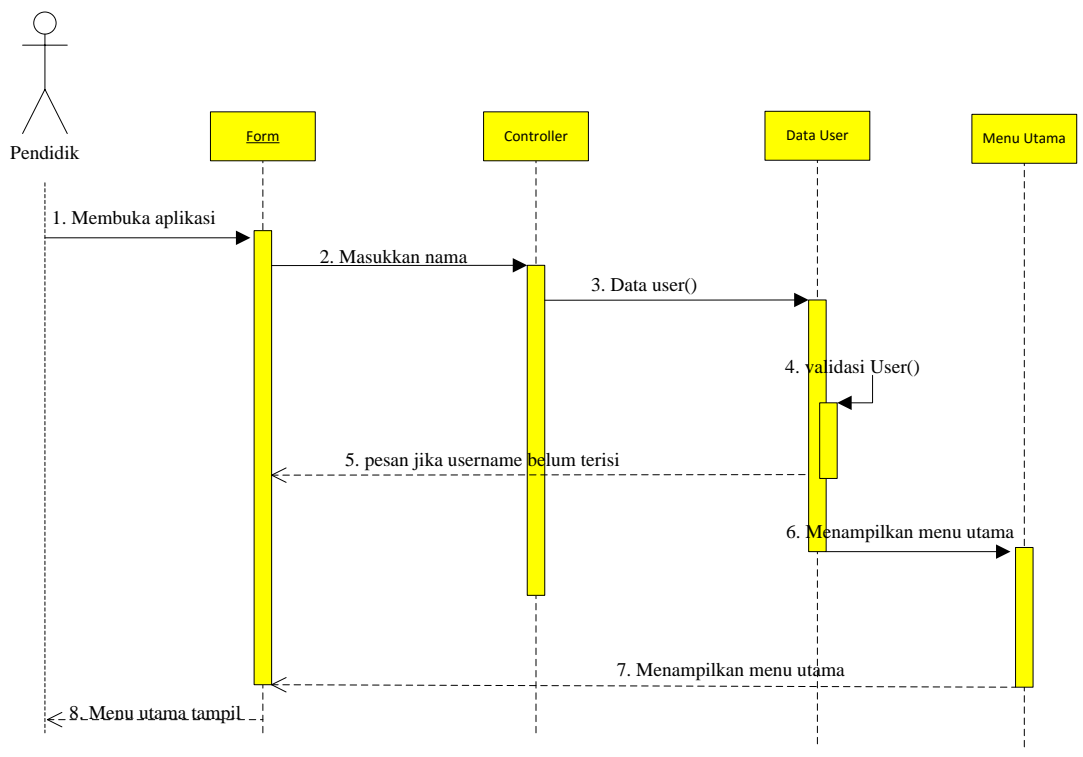

\section{Hasil dan Pembahasan}

Gambar 3. Sequence Diagram Login

Berdasarkan analisis dari desain sistem yang telah dilakukan, maka telah diimplementasikan sketsa gambar dan tulisan berbasis android. Dalam pembuatan aplikasi ini, digunakan bahasa pemrograman Java dengan menggunakan MySQL sebagai media penyimpanan data gambar. Sistem ini ditujukan kepada setiap peserta didik, agar memudahkan pendidik bilamana saat menjelaskan suatu simbol rumus tetapi peserta didik kurang memahami maka dari itu ada sketsa gambar dan tulisan berguna sebagai penjelas.

\subsection{Pengujian Versi Sistem Operasi Android}

Tabel 2. Pengujian Versi Sistem Operasi

\begin{tabular}{|l|c|c|c|}
\hline \multirow{2}{*}{ Merk } & Sistem Operasi & \multicolumn{2}{|c|}{ Hasil pengujian } \\
\cline { 3 - 4 } & $\begin{array}{c}\text { Dapat } \\
\text { Menjalankan } \\
\text { Aplikasi }\end{array}$ & $\begin{array}{c}\text { Tidak Dapat } \\
\text { Menjalankan } \\
\text { Aplikasi }\end{array}$ \\
\hline $\begin{array}{l}\text { Samsung galaxy } \\
\text { grand neo plus }\end{array}$ & Kitkat v4.4.4 & $\checkmark$ & \\
\hline Asus 2 laser & Lollipop v5.0 & $\checkmark$ & \\
\hline Huawei Y3ii & Lollipop v5.1 & $\checkmark$ & \\
\hline Redmi 3s & $\begin{array}{c}\text { Marshmallow } \\
\text { v6.0.1 }\end{array}$ & $\checkmark$ & \\
\hline $\begin{array}{l}\text { Samsung galaxy J2 } \\
\text { Prime }\end{array}$ & $\begin{array}{c}\text { Marshmallow } \\
\text { v6.0.1 }\end{array}$ & $\checkmark$ & \\
\hline
\end{tabular}

Berdasarkan Tabel 2. pengujian versi sistem operasi Android, bahwa aplikasi dapat berjalan pada minimum versi Kitkat v4.4.4, Lollipop v5.0, Lollipop v5.1, Marshmallow v6.0.1.

a. Pengujian Provider

Tabel 3. Pengujian Provider

\begin{tabular}{|c|l|l|l|l|}
\hline No & Sumber (Pendidik) & Tujuan (Pendidik) & Jarak & Waktu \\
\hline \multirow{2}{*}{1} & Wifi & Indosat (4G ) & \multirow{2}{*}{$4,5 \mathrm{KM}$} & \multirow{2}{*}{6 Detik } \\
\cline { 2 - 3 } & Bantul & Bantul & \multirow{2}{*}{$13.5 \mathrm{KM}$} & \multirow{2}{*}{4 Detik } \\
\hline \multirow{2}{*}{2} & Wifi & Indosat (4G ) & Prambanan & \\
\cline { 2 - 3 } & Bantul & \multicolumn{2}{|c}{} \\
\hline
\end{tabular}




\begin{tabular}{|c|c|c|c|c|}
\hline \multirow{2}{*}{3} & Wifi & Indosat ( 4G ) & \multirow{2}{*}{$15.3 \mathrm{KM}$} & \multirow{2}{*}{4 Detik } \\
\hline & Bantul & Klaten A & & \\
\hline \multirow{2}{*}{4} & Wifi & Indosat ( 4G ) & \multirow{2}{*}{$22.5 \mathrm{KM}$} & \multirow{2}{*}{6 Detik } \\
\hline & Bantul & Klaten B & & \\
\hline \multirow{2}{*}{5} & Wifi & Indosat ( 4G ) & \multirow{2}{*}{$148.5 \mathrm{KM}$} & \multirow{2}{*}{6 Detik } \\
\hline & Bantul & Rembang & & \\
\hline \multirow{2}{*}{6} & Indosat ( 4G ) & Indosat ( 4G ) & \multirow{2}{*}{$4.5 \mathrm{KM}$} & \multirow{2}{*}{4 Detik } \\
\hline & Bantul & Bantul & & \\
\hline \multirow{2}{*}{7} & Indosat ( 4G ) & Indosat ( 4G ) & \multirow{2}{*}{$13.5 \mathrm{KM}$} & \multirow{2}{*}{10 Detik } \\
\hline & Bantul & Prambanan & & \\
\hline \multirow{2}{*}{8} & Indosat ( 4G ) & Indosat ( 4G ) & \multirow{2}{*}{$15.3 \mathrm{KM}$} & \multirow{2}{*}{6 Detik } \\
\hline & Bantul & Klaten A & & \\
\hline \multirow{2}{*}{9} & Indosat ( 4G ) & Indosat ( 4G ) & \multirow{2}{*}{$22.5 \mathrm{KM}$} & \multirow{2}{*}{7 Detik } \\
\hline & Bantul & Klaten B & & \\
\hline \multirow{2}{*}{10} & Indosat ( 4G ) & Indosat ( 4G ) & \multirow{2}{*}{$148.5 \mathrm{KM}$} & \multirow{2}{*}{6 Detik } \\
\hline & Bantul & Rembang & & \\
\hline 11 & Telkomsel ( 4G ) & Indosat ( 4G ) & $45 \mathrm{KM}$ & 7 Detik \\
\hline 11 & Bantul & Bantul & $4.5 \mathrm{~N} 1 \mathrm{n}$ & / Dеपк \\
\hline 12 & Telkomsel ( $4 \mathrm{G}$ ) & Indosat ( 4G ) & & \\
\hline 12 & Bantul & Prambanan & $13.5 \mathrm{KIV}$ & O DetIK \\
\hline 13 & Telkomsel ( 4G ) & Indosat ( 4G ) & $155 \mathrm{KM}$ & 5 Detik \\
\hline 13 & Bantul & Klaten A & Г. К KIV & J DEUK \\
\hline 14 & Telkomsel ( 4G ) & Indosat ( 4G ) & $225 \mathrm{KM}$ & 4 Detik \\
\hline 14 & Bantul & Klaten B & ZL.J KVI & 4 DetiK \\
\hline & Telkomsel ( $4 \mathrm{G}$ ) & Indosat ( 4G ) & $1485 \mathrm{KM}$ & \\
\hline 15 & Bantul & Rembang & $148.5 \mathrm{KM}$ & 3 Det1K \\
\hline & XL ( 4G ) & Indosat ( 4G ) & & \\
\hline 16 & Bantul & Bantul & $4.5 \mathrm{KM}$ & 3 Det1K \\
\hline 17 & $\mathrm{XL}(4 \mathrm{G})$ & Indosat ( 4G ) & $135 \mathrm{KM}$ & 7 Detik \\
\hline 17 & Bantul & Prambanan & $13.5 \mathrm{KIV}$ & I DetiK \\
\hline 18 & XL ( 4G ) & Indosat ( 4G ) & $153 \mathrm{KM}$ & 6 Detik \\
\hline 18 & Bantul & Klaten A & Г. К KIVI & о Dеपा \\
\hline 19 & XL ( 4G ) & Indosat ( 4G ) & $225 \mathrm{KM}$ & 9 Detik \\
\hline 19 & Bantul & Klaten B & $\angle 2 . J \mathrm{KIV}$ & 9 Detा \\
\hline 20 & XL ( 4G ) & Indosat ( 4G ) & $1485 \mathrm{KM}$ & 7 Detik \\
\hline 20 & Bantul & Rembang & $148.5 \mathrm{KIVI}$ & T DetК \\
\hline 21 & Axis ( 4G) & Indosat ( 4G ) & $45 \mathrm{KM}$ & 4 Detik \\
\hline 21 & Bantul & Bantul & $4 . J \mathrm{KIVI}$ & 4 DetIK \\
\hline 22 & Axis (4G) & Indosat ( 4G ) & $135 \mathrm{KM}$ & 8 Detik \\
\hline 22 & Bantul & Prambanan & $13.5 \mathrm{KVI}$ & о DеtIK \\
\hline 23 & Axis ( 4G) & Indosat ( 4G ) & $153 \mathrm{KM}$ & 7 Detik \\
\hline 23 & Bantul & Klaten A & $15.3 \mathrm{KIM}$ & I DeuK \\
\hline 24 & Axis ( 4G) & Indosat ( 4G ) & & \\
\hline 24 & Bantul & Klaten B & $22.5 \mathrm{KIVI}$ & 3 DetıK \\
\hline 25 & Axis (4G) & Indosat ( 4G ) & $148.5 \mathrm{KM}$ & 5 Detik \\
\hline
\end{tabular}




\begin{tabular}{|c|c|c|c|c|}
\hline & Bantul & Rembang & & \\
\hline \multirow{2}{*}{26} & Three( 4G) & Indosat ( 4G ) & \multirow{2}{*}{$4.5 \mathrm{KM}$} & \multirow{2}{*}{13 Detik } \\
\hline & Bantul & Bantul & & \\
\hline \multirow{2}{*}{27} & Three( 4G ) & Indosat ( 4G ) & \multirow{2}{*}{$13.5 \mathrm{KM}$} & \multirow{2}{*}{11 Detik } \\
\hline & Bantul & Prambanan & & \\
\hline \multirow{2}{*}{28} & Three( 4G ) & Indosat ( 4G ) & \multirow{2}{*}{$15.3 \mathrm{KM}$} & \multirow{2}{*}{9 Detik } \\
\hline & Bantul & Klaten A & & \\
\hline \multirow{2}{*}{29} & Three( 4G) & Indosat ( 4G ) & \multirow{2}{*}{$22.5 \mathrm{KM}$} & \multirow{2}{*}{10 Detik } \\
\hline & Bantul & Klaten B & & \\
\hline \multirow{2}{*}{30} & Three( 4G ) & Indosat ( 4G ) & \multirow{2}{*}{$148.5 \mathrm{KM}$} & \multirow{2}{*}{7 Detik } \\
\hline & Bantul & Rembang & & \\
\hline \multirow{2}{*}{31} & Wifi & Indosat ( 3G ) & \multirow{2}{*}{$4.5 \mathrm{KM}$} & \multirow{2}{*}{8 Detik } \\
\hline & Bantul & Bantul & & \\
\hline \multirow{2}{*}{32} & Wifi & Indosat ( 3G ) & \multirow{2}{*}{$13.5 \mathrm{KM}$} & \multirow{2}{*}{6 Detik } \\
\hline & Bantul & Prambanan & & \\
\hline \multirow{2}{*}{33} & Wifi & Indosat ( 3G ) & \multirow{2}{*}{$15.3 \mathrm{KM}$} & \multirow{2}{*}{11 Detik } \\
\hline & Bantul & Klaten A & & \\
\hline \multirow{2}{*}{34} & Wifi & Indosat ( 3G ) & $225 \mathrm{VM}$ & 10 Dotik \\
\hline & Bantul & Klaten B & $22.5 \mathrm{KVI}$ & 10 Dеपा \\
\hline 35 & Wifi & Indosat ( 3G ) & $1485 \mathrm{KM}$ & 9 Detik \\
\hline 35 & Bantul & Rembang & $148.5 \mathrm{KIV}$ & 9 Dеtiк \\
\hline 36 & Indosat ( 3G ) & Indosat ( 3G ) & $45 \mathrm{KM}$ & 9 Detik \\
\hline 30 & Bantul & Bantul & $4.0 \mathrm{~N}$ (1) & ( \\
\hline 27 & Indosat ( $3 G$ ) & Indosat ( 3G ) & $125 \mathrm{VM}$ & 6 Dotil- \\
\hline II & Bantul & Prambanan & 15.5 KIVI & O DCUार \\
\hline & Indosat ( $3 G$ ) & Indosat ( 3G ) & & \\
\hline 38 & Bantul & Klaten A & $15.3 \mathrm{KM}$ & 6 Detik \\
\hline 39 & Indosat ( 3G ) & Indosat ( 3G ) & $225 \mathrm{KM}$ & 9 Detik \\
\hline 39 & Bantul & Klaten B & $22.3 \mathrm{NIVI}$ & प्रण \\
\hline 10 & Indosat ( $3 G$ ) & Indosat ( 3G ) & $1405 \mathrm{KM}$ & 14 Dotik \\
\hline 40 & Bantul & Rembang & $140.5 \mathrm{KIVI}$ & 14 Detuk \\
\hline 41 & Telkomsel ( 3G ) & Indosat ( 3G ) & $45 \mathrm{KM}$ & 7 Detik \\
\hline & Bantul & Bantul & & \\
\hline 12 & Telkomsel ( 3G ) & Indosat ( 3G ) & $135 \mathrm{KM}$ & 12 Detik \\
\hline 42 & Bantul & Prambanan & 15.5 KIVI & \\
\hline 12 & Telkomsel ( 3G ) & Indosat ( 3G ) & $152 \mathrm{VM}$ & 7 Dotil. \\
\hline 43 & Bantul & Klaten A & $15.3 \mathrm{KM}$ & / Detık \\
\hline 44 & Telkomsel ( 3G ) & Indosat ( 3G ) & $225 \mathrm{KM}$ & 12 Detik \\
\hline 44 & Bantul & Klaten B & & \\
\hline 15 & Telkomsel ( 3G ) & Indosat ( 3G ) & $1485 \mathrm{KM}$ & 24 Detik \\
\hline $4 J$ & Bantul & Rembang & $140.5 \mathrm{NIVI}$ & \\
\hline 16 & XL ( 3G ) & Indosat ( 3G ) & $45 \mathrm{KM}$ & S Dotil. \\
\hline 40 & Bantul & Bantul & $4.5 \mathrm{KM}$ & 8 DetuK \\
\hline 47 & $\mathrm{XL}(3 \mathrm{G})$ & Indosat ( $3 G$ ) & $13.5 \mathrm{KM}$ & 7 Detik \\
\hline
\end{tabular}




\begin{tabular}{|c|c|c|c|c|}
\hline & Bantul & Prambanan & & \\
\hline \multirow{2}{*}{48} & $\mathrm{XL}(3 \mathrm{G})$ & Indosat ( $3 G$ ) & \multirow{2}{*}{$15.3 \mathrm{KM}$} & \multirow{2}{*}{9 Detik } \\
\hline & Bantul & Klaten A & & \\
\hline \multirow{2}{*}{49} & XL ( 3G) & Indosat ( $3 G$ ) & \multirow{2}{*}{$22.5 \mathrm{KM}$} & \multirow{2}{*}{8 Detik } \\
\hline & Bantul & Klaten B & & \\
\hline \multirow{2}{*}{50} & XL ( 3G ) & Indosat ( $3 G$ ) & \multirow{2}{*}{$148.5 \mathrm{KM}$} & \multirow{2}{*}{7 Detik } \\
\hline & Bantul & Rembang & & \\
\hline \multirow{2}{*}{51} & Axis ( 3G ) & Indosat ( $3 G$ ) & \multirow{2}{*}{$4.5 \mathrm{KM}$} & \multirow{2}{*}{11 Detik } \\
\hline & Bantul & Bantul & & \\
\hline \multirow{2}{*}{52} & Axis ( $3 G$ ) & Indosat ( $3 G$ ) & \multirow{2}{*}{$13.5 \mathrm{KM}$} & \multirow{2}{*}{13 Detik } \\
\hline & Bantul & Prambanan & & \\
\hline \multirow{2}{*}{53} & Axis ( $3 G$ ) & Indosat ( $3 G$ ) & \multirow{2}{*}{$15.3 \mathrm{KM}$} & \multirow{2}{*}{14 Detik } \\
\hline & Bantul & Klaten A & & \\
\hline \multirow{2}{*}{54} & Axis ( 3G ) & Indosat ( $3 G$ ) & \multirow{2}{*}{$22.5 \mathrm{KM}$} & \multirow{2}{*}{9 Detik } \\
\hline & Bantul & Klaten B & & \\
\hline \multirow{2}{*}{55} & Axis ( 3G ) & Indosat ( $3 G$ ) & \multirow{2}{*}{$148.5 \mathrm{KM}$} & \multirow{2}{*}{11 Detik } \\
\hline & Bantul & Rembang & & \\
\hline \multirow{2}{*}{56} & Three( $3 G$ ) & Indosat ( $3 G$ ) & \multirow{2}{*}{$4.5 \mathrm{KM}$} & \multirow{2}{*}{10 Detik } \\
\hline & Bantul & Bantul & & \\
\hline \multirow{2}{*}{57} & Three( $3 G$ ) & Indosat ( $3 G$ ) & \multirow{2}{*}{$13.5 \mathrm{KM}$} & \multirow{2}{*}{18 Detik } \\
\hline & Bantul & Prambanan & & \\
\hline \multirow{2}{*}{58} & Three( $3 G$ ) & Indosat ( $3 G$ ) & \multirow{2}{*}{$15.3 \mathrm{KM}$} & \multirow{2}{*}{14 Detik } \\
\hline & Bantul & Klaten A & & \\
\hline & Three( $3 G$ ) & Indosat ( $3 G$ ) & & 9 Detik \\
\hline 59 & Bantul & Klaten B & $22.5 \mathrm{KM}$ & \\
\hline 60 & Three( $3 \mathrm{G}$ ) & Indosat ( $3 G$ ) & & \\
\hline 60 & Bantul & Rembang & $148.5 \mathrm{KM}$ & 9 Det1K \\
\hline
\end{tabular}

Berdasarkan pengujian provider diatas dari 60 percobaaan yang telah dilakukan memiliki rata-rata waktu koneksi adalah 8,33 detik.

\section{b. Hasil Pengujian Pengguna}

Pengujian pengguna aplikasi dari kuesioner kepada 30 responden didapatkan hasil sebagai berikut: 


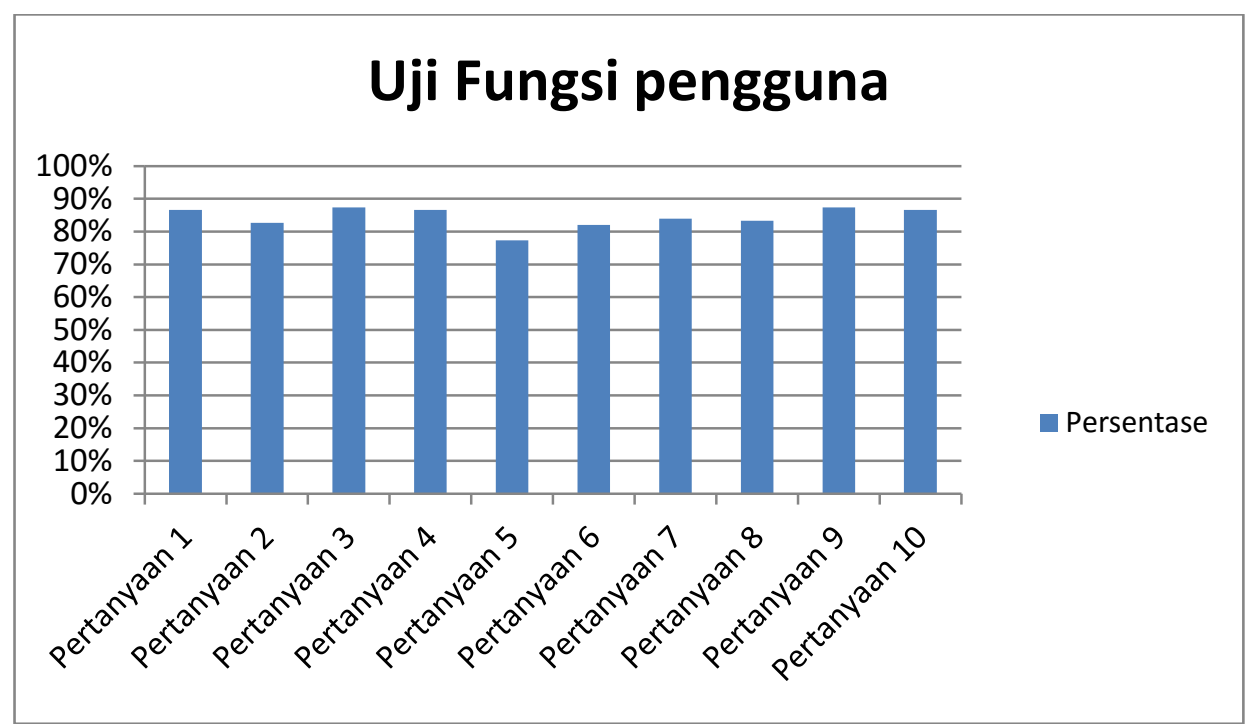

Gambar 4. Grafik Uji Pengguna

Berdasarkan Hasil rata-rata yang sudah didapat dari pengujian menggunakan kuesioner dan dihitung menggunakan metode Skala Likert adalah 84,4 \%, maka dapat disimpulkan bahwa pengujian menggunakan kuesioner termasuk dalam kriteria "Sangat Baik".

\section{c. Implementasi Hasil Video Call pendidik dan peserta didik}

Sebagai penjelasan pengujian pada gambar 4 dan gambar 5, pendidik melakukan video call kepada peserta didik melakukan pembelajaran jarak jauh.

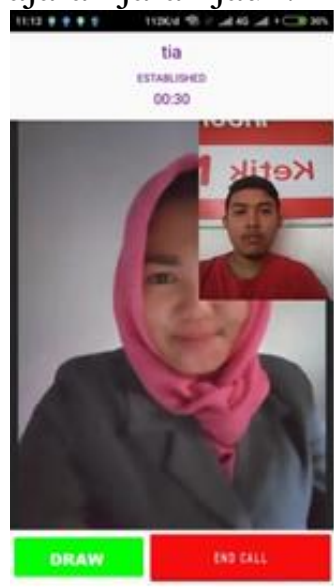

Gambar 4. Tampilan Video Call Peserta Didik

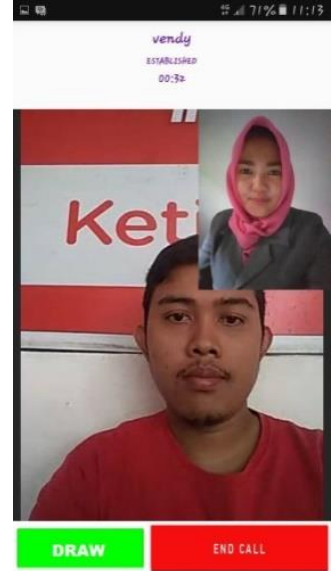

Gambar 5. Tampilan Video Call Pendidik

\section{d. Implementasi Hasil Sketsa Gambar Dan Tulisan}


Gambar 6 menunjukkan bahwa pengujian pemanggilan data gambar dari server dan data gambar pada database server telah berjalan dengan baik seperti yang diharapkan.

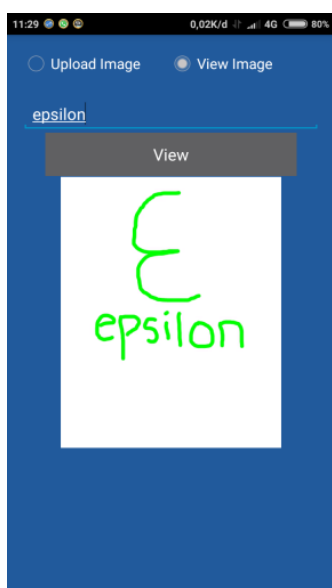

\section{Penutup}

\subsection{Kesimpulan}

Kesimpulan yang diperoleh dari hasil pengujian aplikasi sketsa gambar dan tulisan pada video call berbasis Android adalah sebagai berikut :

1. Implementasi sketsa gambar dan tulisan pada aplikasi, sketsa gambar dan tulisan dibuat dan disimpan terlebih dahulu kemudian diupload oleh pendidik.

2. Berdasarkan hasil pengujian sistem operasi Android, aplikasi ViCall dapat berjalan pada minimal speksifikasi saat pengujian yaitu Kitkat v4.4.4.

3. Berdasarkan dari hasil pengujian provider yang telah dilakukan, aplikasi ViCall menghasilkan rata-rata waktu koneksi adalah 8,33 detik.

4. Hasil dari uji kuesioner mendapatkan nilai rata-rata $84,4 \%$ dengan kriteria "Sangat Baik“.

\subsection{Saran}

Saran-saran yang bisa ditambahkan pada aplikasi ViCall adalah sebagai berikut :

1. Menambahkan penyimpanan sketsa gambar dan tulisan dengan ekstensi yang lebih banyak lagi. Contoh : JPG / JPEG, GIF, BMP, dan TIFF

2. Membuat sketsa gambar dan tulisan bisa secara real time.

3. Perkembangan aplikasi ViCall kedepan diharapkan bisa dibuat multi Conference.

\section{Daftar Pustaka}

[1]Dennis, Alan dkk. 2005. System Analysis Design with UML version 2.0 an Object-Oriented Approach. Wiley. Indiana Univertity.

[2]Herryawan, Kusti. 2009. Video Conference. Pusat Teknologi Informasi dan Komunikasi Pendidikan Departemen Pendidikan Nasional.

[3]Ferdianti, Ferina dkk. 2012. Perancangan Sistem Informasi Video Conference Untuk Mendukung Rapat. Universitas Gunadarma.

[4]Hardyanto, R. Hafid. 2016. Pengembangan Dan Implementasi E-Learning Menggunakan Moodle Dan Vicon Untuk Pelajaran Pemrograman Web Di Smk. Universitas PGRI Yogyakarta. 
[5]Ifdil. 2013. Konseling Online Sebagai Salah Satu Bentuk Pelayanan E-konseling. Unniversitas Negeri Padang.

[6]Silitonga, Yoice dkk. 2012. Analisa Perbandingan Kualitas Belajar - Mengajar Antara Metode Face to Face dan Video Conference. Universitas Sriwijaya Inderalaya. 